\title{
Efeitos negativos da ocupação irregular nos serviços ecossistêmicos aquáticos do município de Várzea Grande - MT1
}

\section{Negative effects of occupation on aquatic ecosystem services in the municipality of Várzea Grande - MT}

\author{
Santos, Cézar Clemente Pires dos'; Rezende, Ana Paula 2; Rosin, Jeane \\ Aparecida Rombi de Godoy 3; Moraes, Carmelina Suquere de ${ }^{4}$
}

\author{
I UNIVAG - Centro Universitário, AV. Dom Orlando Chaves, n².655 Bairro \\ Cristo Rei - Várzea Grande Mato Grosso, Brasil, cezarbiologo@gmail.com \\ 2 UNIVAG - Centro Universitário, p-rezende@hotmail.com \\ 3 UNIVAG - Centro Universitário, urbanista.jeane@gmail.com \\ 4 UNIVAG - Centro Universitário, carmelinasuquere@gmail.com
}

\begin{abstract}
RESUMO
Este artigo discute os efeitos da ocupação urbana em áreas de preservação permanente e as possibilidades de integração entre ocupação urbana e a manutenção de serviços ecossistêmicos tendo em vista a importância de suas funções primordiais. Estas funções abordam a capacidade dos ecossistemas em regularem os processos ecológicos essenciais de suporte à vida e de regulação relacionadas aos aspectos estruturais dos ecossistemas, como a cobertura vegetal e habitat, tão essenciais para a conservação biológica, genética e para a preservação de processos evolucionários. A partir deste enfoque, o presente trabalho tem como objetivo mapear o uso e ocupação do solo nas áreas de preservação permanente em um córrego urbano no município de Várzea Grande - MT, a fim de verificar os efeitos negativos de sua ocupação. Para o levantamento de uso e ocupação do solo nas APP's do Córrego Água Limpa foi utilizado o sistema de informação geográfica, que permitiu a visualização, edição e análise de dados georreferenciados, os quais foram organizados em três etapas divididas em: Pré-processamento, Processamento e Pós-Geoprocessamento. Os resultados apontaram um elevado estágio de antropização nas APP'S afetando os serviços ecossistêmicos de regulação como o controle dos processos erosivos e de suporte como a formação dos solos.
\end{abstract}

Palavras-chave: APP, SIG, Ocupação antrópica.

\begin{abstract}
This article discusses the effects of urban occupation on permanent preservation areas and the possibilities of integration between urban occupation and the maintenance of ecosystem services in view of the importance of their primary functions. These functions address the ability of ecosystems to regulate the essential ecological processes of life support and regulation related to the structural aspects of ecosystems, such as vegetation cover and habitat, so

\footnotetext{
${ }^{1}$ SANTOS, C.C.P; REZENDE, A.P.; ROSIN, J.A.R.G.;MORAES, C.S. Efeitos negativos da ocupação irregular nos serviços ecossistêmicos aquáticos do município de Várzea Grande - MT In: II SIMPÓSIO NACIONAL DE GESTÃO E ENGENHARIA URBANA: SINGEURB, 2019, São Paulo. Anais... Porto Alegre: ANTAC, 2019.
} 
essential for biological conservation, genetics and preservation of evolutionary processes. Based on this approach, this work aims to map the use and occupation of the soil in the areas of permanent preservation in an urban stream in the municipality of Várzea Grande - MT, in order to verify the negative effects of its occupation. For the survey of land use and occupation in the Agua Limpa Creek APP, the geographic information system was used, which allowed the visualization, editing and analysis of georeferenced data, which were organized in three stages divided into: Pre-processing, Processing and Post-Geoprocessing. The results pointed out a high stage of anthropization in the APPs affecting the ecosystem services of regulation as the control of the erosive and support processes as the formation of the soils.

Keywords: APP, GIS, Anthropic occupation.

\section{INTRODUÇÃO}

O termo ecossistema foi originalmente concebido no campo da biologia para salientar a interação entre organismos da natureza (TANSLEY, 1935). De modo geral, um sistema pode ser caracterizado pela existência de componentes que funcionam de modo interligado. Um ecossistema ou sistema ecológico é constituído por um agrupamento de componentes abióticos e bióticos, presentes em um determinado local, que estão em interação por meio do fluxo de energia e da ciclagem de materiais. Os ecossistemas podem ser terrestres e marinhos, interiores ou litorâneos, naturais ou modificados, como os rurais ou urbanos.

Os serviços ecossistêmicos de suporte passaram a ser considerados nos sistemas de classificação não só como uma categoria, mas como funções ecossistêmicas dos processos ecológicos como: a produção de oxigênio atmosférico; a ciclagem de nutrientes; a formação e retenção de solos; e a ciclagem da água, tornando o mesmo necessário para a produção de todos os serviços ecossistêmicos terrestres e marinhos modificados ou não (MMA, 2018).

Para Bennet (2005), o papel dos serviços ecossistêmicos na melhoria da qualidade ambiental das cidades, atuam como suporte à gestão de áreas verdes na malha urbana, e ajudam na promoção de saúde e expectativa de vida. Quando se relaciona o papel dos serviços ecossistêmicos na qualidade ambiental das cidades e a qualidade de vida da população, verifica-se que as florestas estão entre os ecossistemas mais importantes, pois estão claramente relacionados a muitos dos benefícios pertinentes às categorias de produção, suporte, regulação e cultural.

Num contexto geral, as ocupações irregulares em APP's podem ser constatadas em casos de loteamentos residenciais clandestinos ou não, promovidos por população de baixa renda ou até mesmo por pessoas com alto poder aquisitivo, a exemplo dos condomínios fechados e conjuntos residenciais que ocupam essas áreas de maneira irregular.

A falta de planejamento urbano, tem sido responsável pelas ocupações irregulares de vários espaços caracterizados como APP's no Município de Várzea Grande - MT, igual a realidade de muitas das cidades brasileiras, muitas vezes com a anuência do Poder Público. Diante do quadro acima descrito, o presente artigo tem como objetivo mapear o uso e ocupação do solo nas áreas de preservação permanente em um córrego urbano no município de Várzea Grande - MT, para verificar os efeitos negativos da ocupação urbana irregular nos serviços ecossistêmicos de regulação e suporte.

\section{MATERIAIS E MÉTODOS}

\section{1 Área de Estudo}

O presente estudo foi realizado no córrego Água Limpa, localizado no município de Várzea Grande - MT, no qual se estende por uma rede de drenagem de 7,4 Km, entre cursos d'água de primeira e segunda ordem, margeando os bairros de Água Limpa, Jardim Aeroporto, Planalto Ipiranga, Vila Ipase, Vila Pirineu, Santa Maria I, Costa Verde e região central do município como apresentado na figura 1. Sua nascente está localizada na área central da cidade (latitude 15³9'5,96"S e longitude 56 $7^{\prime}$ '54,54"W), às margens da Avenida Castelo 
Branco, hoje implantado sobre o mesmo o ginásio poliesportivo Júlio Domingos de Campos (Fiotão).

Figura 1 - Mapa de localização do Córrego Água Limpa.

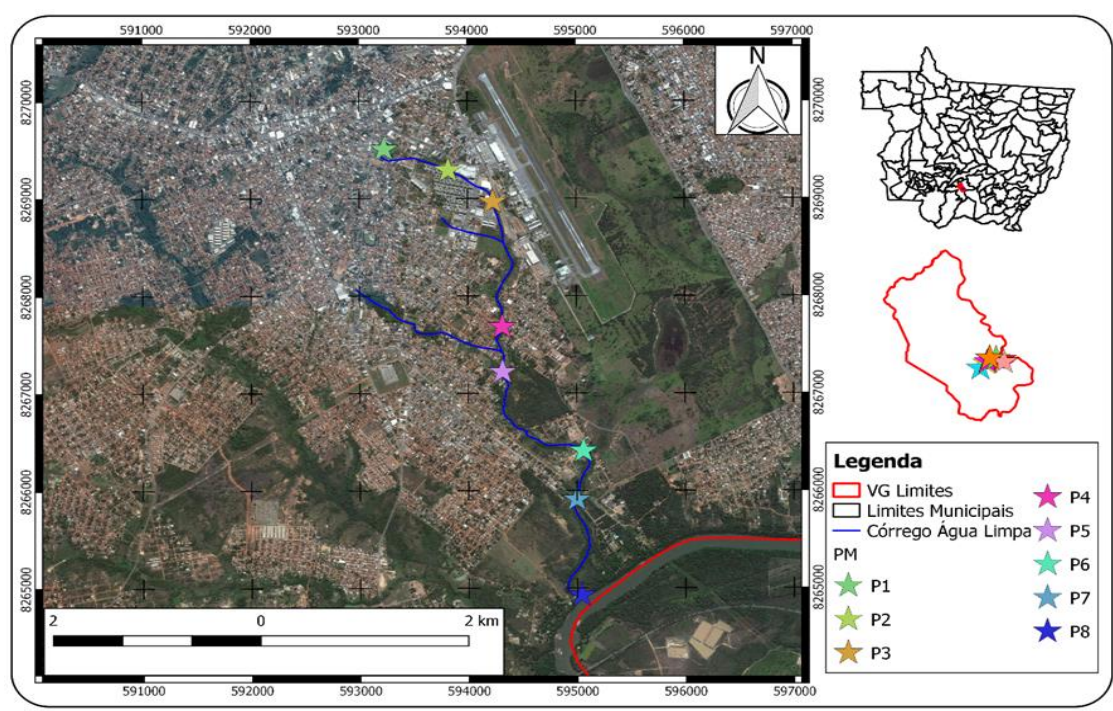

Fonte: Santos (2018).

\subsection{Geotecnologias para levantamento de uso e ocupação do solo}

Para a realização de levantamento de uso e ocupação do solo nas áreas de preservação permanente do Córrego Água Limpa, foi utilizado SIG, que permite a visualização, edição e análise de dados georreferenciados, aplicada a metodologia proposta por Góes e Xavierda-Silva (1996), subdividindo o estudo em três a etapas: Pré-Geoprocessamento, Processamento e Pós-Geoprocessamento.

O Pré-Geoprocessamento consiste na aquisição e organização dos dados, por meio de levantamento de dados vetoriais e raster, cobrindo a região do córrego Água Limpa (FLORENZANO, 2007).

Foram utilizadas imagens de alta resolução espacial para averiguar se a hidrografia representada na base cartográfica correspondia à drenagem atual do município. No que diz respeito a etapa do processamento, foram realizadas operações matemáticas para associar informações dos dados vetoriais (nascentes e rede hidrográfica), para geração das APP's seguindo os parâmetros estabelecidos pelo código florestal.

A definição das classes de cobertura do solo foi baseada no método utilizado por Florenzano (2007), em que se distinguem os objetos em imagens Raster, analisando os elementos como: cor; textura; tamanho; forma; sombra; altura; padrão e localização.

Na etapa de Pós-Geoprocessamento, foram elaborados mapas com a inserção de temas, legendas, escalas, configuração dos textos e a criação dos layouts. A organização, produção e interpretação dos dados foram armazenadas em um banco de dados digital. (LONGLEY et al, 2013).

\section{RESULTADOS E DISCUSSÕES}

Com intuito de visualizar espacialmente o uso e ocupação do solo nas áreas de preservação permanente do córrego Água Limpa, o presente estudo delimitou 4 regiões, sendo elas representadas pela região Central, Região Noroeste, Região Sudoeste e Região Sul. Uma vez que tais ocupações estão relacionadas ao processo de urbanização que o município de Várzea Grande vem sofrendo nos últimos 20 anos. 
A Lei 12.651/2012 (Novo Código Florestal), estabelece normas de proteção sobre áreas de preservação permanente (APP's), florestas e demais formas de vegetação situadas às margens de lagos ou rios, sendo seu limite de 30 metros para cada margem em zonas urbanas e para nascentes a área de proteção está estabelecida através de um raio de 50 metros da nascente. O uso e ocupação do solo, nas APP's do presente curso d'água apresentou 75,1\% de vegetação nativa íntegra, mesmo tendo apresentado processo acelerado de uso e ocupação em suas áreas de APP's (tabela 1). Já a somatória das classes - área construída e área impermeável representam $13,9 \%$ de toda área delimitada como APP's, sendo sua maioria localizada na região central e região noroeste (tabela 1).

Tabela 1 - Uso e ocupação do solo na área de APP do córrego Água limpa.

Uso e ocupação do solo

Métricas Área construída Área impermeável Solo exposto Vegetação Água Total da área (ha)

\begin{tabular}{ccccccc} 
ha & 3,1 & 4,5 & 5,1 & 41,0 & 0,8 & 54,47 \\
$\%$ & 5,7 & 8,2 & 9,4 & 75,1 & 1,6 & 100 \\
\hline
\end{tabular}

Fonte: Os autores

Na região Central, encontram-se inseridos os bairros Ipase, Jardim Aeroporto e bairro Pirineu, essa região faz confronto a leste, onde está localizado o limite do Aeroporto Internacional Marechal Rondon. O estudo realizado nesta região, identificou a presença de vegetação nativa em um trecho ao norte (figura 2), e a presença de ocupações irregulares nas margens da APP, sendo estas representadas por imóveis residenciais. A maior representatividade está associada as áreas impermeáveis, evidenciando elevado estado e antropização, uma vez que nestas classes estão inseridos os grandes empreendimentos comerciais, tendo suas principais vias de acesso ligadas a região central (figura 2). A falta de vegetação identificada no mapeamento (figura 2) evidenciou a vulnerabilidade da região a picos de cheia em períodos chuvosos, de alagamentos no curso d'água em razão da canalização, alterando os serviços ecossistêmicos de regulação da qualidade da água, que por sua vez podem afetar os serviços de regulação do controle de doenças relacionadas a falta de saneamento básico.

Figura 2 - Uso e ocupação do solo na região central do Córrego Água Limpa.

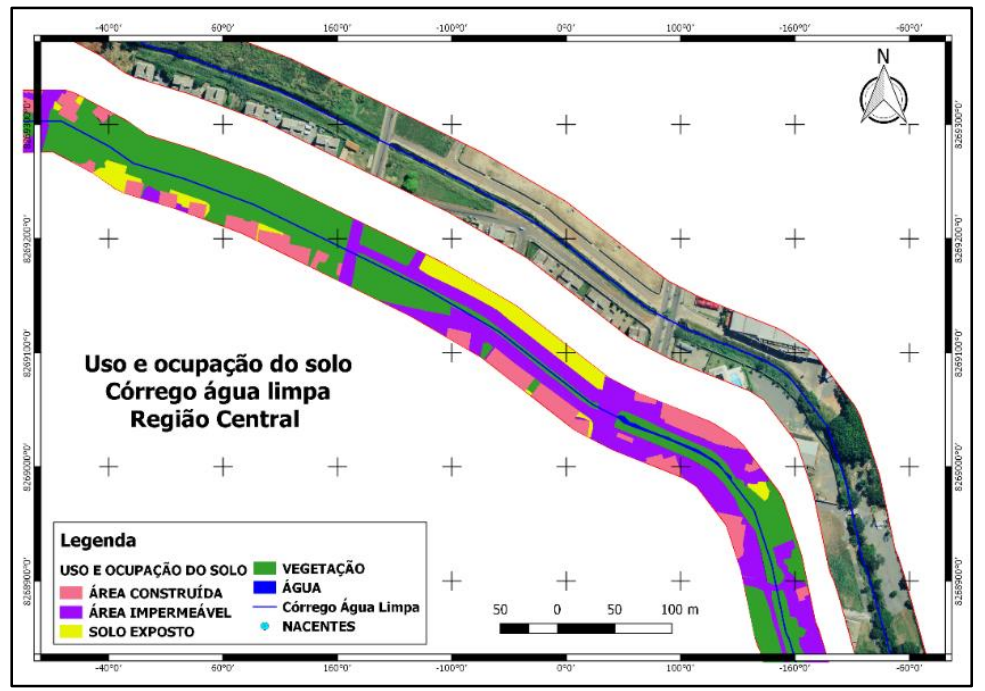

Fonte: Santos (2018). 
A principal nascente do curso d'água está inserida em um local histórico denominado "Ginásio Fiotão". Há quarenta anos, havia uma mina de água conhecida como Poço Velho, onde muitas pessoas, a pé ou com carroças, buscavam água para abastecimento doméstico. No ano de 2018 foi evidenciado alto grau de antropização (figura 3), sendo a maioria de suas classes temáticas mapeadas representada pelas classes (área impermeável e área construída). Ao relacionar a importância histórica da nascente com as características funcionais dos serviços ecossistêmicos culturais, é possível constatar que os serviços culturais estão intimamente ligados a valores e comportamentos humanos, bem como às instituições e padrões sociais, características que fazem com que a percepção dos mesmos seja perdida no decorrer dos tempos (ANDRADE e ROMEIRO 2009).

Figura 3 - Uso e ocupação do solo na região noroeste do Córrego Água Limpa.

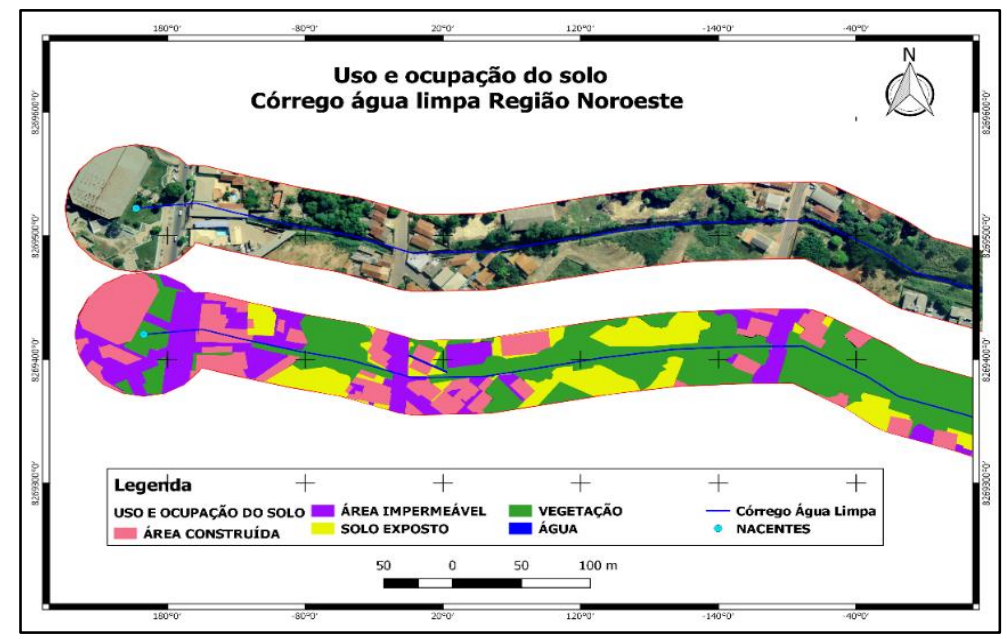

Fonte: Santos (2018)

A região Sudoeste, assim como verificado na região central, apresenta faixa de ocupação irregular nas áreas de APP, sendo essa delimitada junto ao loteamento Santa Maria II (figura 4), esta região não dispõe de infraestrutura básica, como asfalto e espaços públicos destinados à educação e lazer, uma vez que se trata de um bairro ocupado de forma irregular, tendo em sua maioria a presença de remanescentes florestais dentro do perímetro delimitado como APP. A classe vegetação nativa representa em torno de $65 \%$ da área total delimitada com maior representatividade nesta região.

Figura 4 - Uso e ocupação do solo região sudoeste do Córrego Água Limpa.

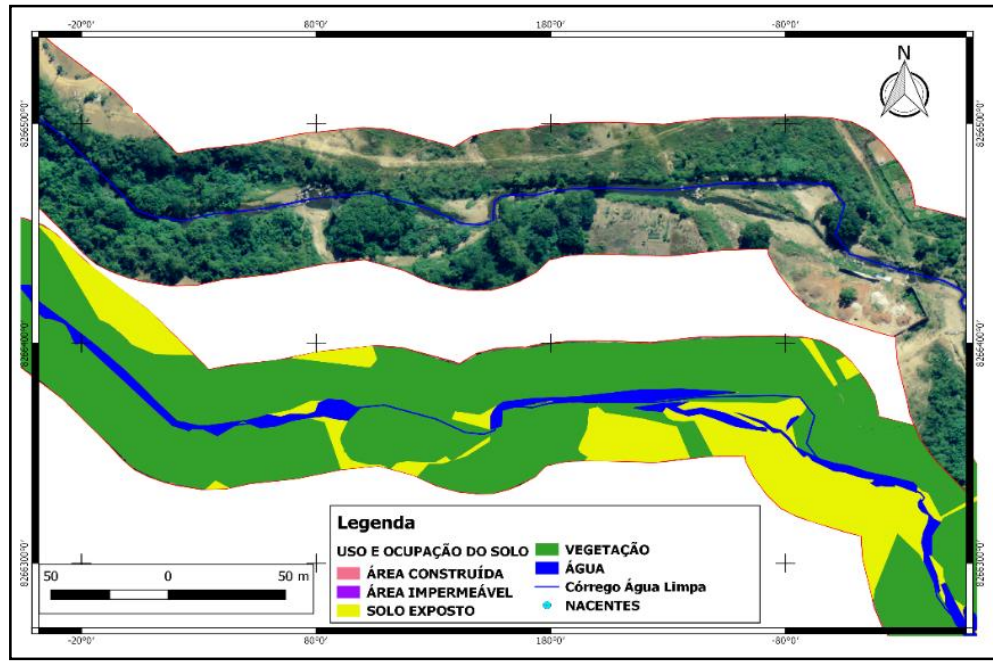

Fonte: Santos (2018). 
A região Sul localiza-se a jusante do rio Cuiabá, e está inserida em uma matriz nativa com características florestais de cerrado (figura 5). O solo exposto foi outra classe temática identificada no mapeamento. O aparecimento desta classe a jusante está associado ao carreamento de sedimentos de montante para jusante do curso d'água, tendo em vista que o transporte de material particulado está diretamente associado ao perfil topográfico da região, cujo relevo apresenta inclinação acima de 40 graus.

A vegetação nativa garante a função de reprodução vegetal, que se traduz também em serviços ecossistêmicos essenciais para a manutenção do ecossistema. No que se refere às funções classificadas como de habitat, a vegetação exerce um papel fundamental, pois fornece alimentação, refúgio e abrigo para espécies animais, contribuindo para a manutenção da diversidade genética e biológica de processos evolucionários.

Por fim a área florestada associada ao curso hídrico, possibilita que a função de informação se relacione com a capacidade dos ecossistemas naturais, na medida em contribuírem para a manutenção da saúde humana, desenvolvimento cognitivo, recreação e experiência estética.

Figura 5 - Uso e ocupação do solo região Sul do Córrego Água Limpa.

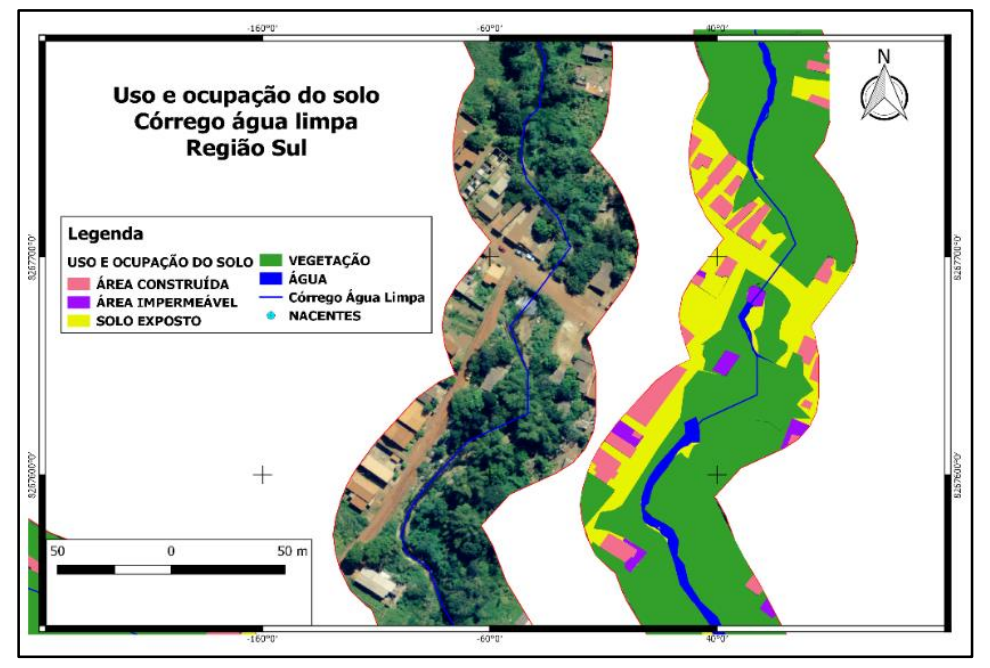

Fonte: Santos (2018).

\section{CONCLUSÕES}

A Geografia aliada às técnicas de geoprocessamento e sensoriamento remoto permitiu compreender o processo de ocupação irregular nas áreas de preservação permanente, evidenciando que a maior parte das APP's estão em desacordo com o novo código florestal de 2012. Os efeitos negativos da ocupação irregular podem gerar efeitos negativos nos serviços ecossistêmicos de regulação afetando o controle dos processos erosivos e alterando a qualidade da água, afetando diretamente a formação do solo e propiciando a dispersão de sementes de espécies vegetais invasoras generalistas.

A legislação brasileira determina regras específicas sobre desenvolvimento urbano e ambiental. Porém, fatores socioeconômicos desafiam a capacidade de gestão territorial refletindo em vulnerabilidade social e ambiental à desastres. Portanto, o emprego de geotecnologias aplicadas no mapeamento das APP's no município, é uma ferramenta importante para o poder público adotar processos de gestão urbana-ambiental, visando contribuir para a melhoria das tomadas de decisões relacionadas à fiscalização para impedir que novas áreas protegidas sejam ocupadas e degradadas.

A análise espacial permitiu evidenciar a evolução temporal da ocupação nas áreas de preservação permanente e os resultados podem nortear os órgãos responsáveis intensificar o 
desenvolvimento de programas de educação ambiental, além de reforçar ações de planejamento territorial e prevenção. Frente a isso, as informações aqui contidas poderão subsidiar futuros projetos de preservação de matas ciliares e zoneamento de áreas de risco.

\section{REFERÊNCIAS}

ANDRADE, Daniel Caixeta; ROMERO, Ademar Ribeiro. Serviços ecossistêmicos e sua importância para o sistema econômico e o bem-estar humano. IE/UNICAMP. n. 155, fev. 2009.

BENNET, E.M., PETERSON, G.D., LEVITT, E.A., 2005. Looking to the future of ecosystem services. Ecosystems 8, 125-132.

DUARTE, Marise Costa de Souza. Meio ambiente sadio: direito fundamental em crise. Curitiba: Juruá, 2003.

FLORENZANO, T. G. Imagens de Satélite para Estudos Ambientais. São Paulo: Oficina de textos, 2002.

Lei $n^{\circ} 12.651$, de 25 de maio de 2012. Dispõe sobre a proteção da vegetação nativa; altera as Leis $n^{\circ}$ s 6.938 , de 31 de agosto de 1981, 9.393, de 19 de dezembro de 1996, e 11.428 , de 22 de dezembro de 2006; revoga as Leis $n^{\circ} \mathrm{s} 4.771$, de 15 de setembro de 1965, e 7.754, de 14 de abril de 1989, e a Medida Provisória n 2.166- 67, de 24 de agosto de 2001; e dá outras providências. Diário Oficial [da] República Federativa do Brasil, Brasília, DF, 25 mai 2012.

LONGLEY, P. A.; Goodchild, M. F.; Maguire, D. J.; Rhind, D. W. Sistemas e ciência da Informação Geográfica. Revisão técnica: Heinrich Hasenack, Eliseu José Weber. $3^{a}$ ed. Porto Alegre:Bookman,2013.

MMA. Convenção da Diversidade Biológica. 2018a. Disponível em: <http://www.mma.gov.br/biodiversidade/convenção-da-diversidade-biológica>. Acesso em: abr. de 2019.

MILLENNIUM ECOSYSTEM ASSESSMENT. Relatório síntese da avaliação ecossistêmica do milênio. Disponível: http://www.maweb.org/documents/document.446.aspx.pdf. Acesso: 17 abr. de 2019.

Resolução n. ${ }^{\circ} 369$, de 28 de março de 2006. Dispõe sobre os casos excepcionais, de utilidade pública, interesse social ou baixo impacto ambiental, que possibilitam a intervenção ou supressão de vegetação em Área de Preservação Permanente-APP. Brasília: DOU de 29/3/2006.

ROMEIRO, A.R., 2000. Sustainable development and institutional change: the role of altruistic behavior. Texto para Discussão, Instituto de Economia/UNICAMP, n²97, junho.

SILVA, L.P.; SANTOS, C.A.G. Análise espacial dos riscos de erosão e inundação na bacia do Rio Cuiabá. In: Revista Brasileira de Recursos Hídricos, v.15, n.3, jul/set 2010, p. 21 - 32.

TANSLEY, Arthur G. The use and abuse of vegetational concepts and terms. Ecology 16, p. 284-307, 1935. 